\title{
Pharmacologic rationale underlying the therapeutic effects of tiotropium/olodaterol in COPD
}

This article was published in the following Dove Press journal:

Therapeutics and Clinical Risk Management

8 October 2015

Number of times this article has been viewed

\author{
Girolamo Pelaia' \\ Alessandro Vatrella ${ }^{2}$ \\ Maria Teresa Busceti' \\ Luca Gallelli ${ }^{3}$ \\ Cecilia Calabrese ${ }^{4}$ \\ Rosa Terracciano ${ }^{3}$ \\ Nicola Lombardo' \\ Rosario Maselli' \\ 'Department of Medical and Surgical \\ Sciences, Magna Græcia University of \\ Catanzaro, Catanzaro, ${ }^{2}$ Department of \\ Medicine and Surgery, University \\ of Salerno, Salerno, ${ }^{3}$ Department \\ of Health Science, Magna Græcia \\ University of Catanzaro, Catanzaro, \\ ${ }^{4}$ Department of Cardio-Thoracic \\ and Respiratory Sciences, Second \\ University of Naples, Naples, Italy
}

\begin{abstract}
Bronchodilators are the most important drugs used for the treatment of chronic obstructive pulmonary disease (COPD). In particular, these therapeutic agents are mostly long-acting compounds utilized via inhalation, and include LAMA (long-acting muscarinic receptor antagonists) and LABA (long-acting $\beta_{2}$-adrenoceptor agonists). Because LAMA and LABA induce bronchodilation by distinct mechanisms of action, LABA/LAMA combinations provide a reciprocal potentiation of the pharmacological effects caused by each component. Hence, many COPD patients who do not achieve a satisfactory control of their symptoms using a single, either LAMA or LABA bronchodilator, can experience relevant benefits with the use of LAMA/LABA fixed combinations. Many different LAMA/LABA combinations have been recently developed and evaluated in randomized clinical trials. In this context, our review focuses on the pharmacological mechanisms underpinning the bronchodilation elicited by the LAMA tiotropium bromide and the LABA olodaterol. We also discuss the results of the most important clinical studies carried out in COPD patients to assess the efficacy and safety of tiotropium/olodaterol combinations.
\end{abstract}

Keywords: LAMA, LABA, tiotropium, olodaterol, dual bronchodilation, tiotropium/olodaterol combinations

\section{Introduction}

Chronic obstructive pulmonary disease (COPD) is a heterogeneous respiratory disorder affecting more than 200 million patients worldwide. ${ }^{1}$ Current knowledge indicates that both prevalence and incidence of this disease are continuously increasing, thus leading COPD to predictably become by 2020 the third leading cause of death in the world. Arising from complex interactions between genetic factors and environmental agents, mainly including tobacco smoke and airborne pollutants, COPD is prominently featured by a scarcely reversible and progressively worsening airflow limitation.

Bronchodilators are the most important drugs used for COPD treatment, and they are usually utilized as inhaled long-acting compounds, including LAMA (long-acting muscarinic receptor antagonists) and LABA (long-acting $\beta_{2}$-adrenoceptor agonists). ${ }^{2}$ The excellent therapeutic profile of both LAMA and LABA depends on their effective ability to counteract the bronchoconstrictive cholinergic tone, which in COPD patients represents the predominant functional cause of airflow limitation. This bronchomotor tone is largely sustained by an excessive amount of acetylcholine (ACh) within the airways of subjects with COPD. High levels of ACh are indeed released by vagal nerve reflexes triggered by stimulation of airway sensory nerve endings. ${ }^{3,4}$ Hence, the increase in baseline cholinergic bronchomotor tone of smokers with COPD is closely
Correspondence: Girolamo Pelaia Department of Medical and Surgical Sciences, Magna Græcia University of Catanzaro, Campus Universitario "S. Venuta", Viale Europa - Località Germaneto, 88I00 Catanzaro, Italy Tel +39096I 3647302

Fax+39096I 3647193

Email pelaia@unicz.it
Therapeutics and Clinical Risk Management 20I5:I I 1563-1572 
related to disease severity. ${ }^{5}$ Once released into the airways from postganglionic parasympathetic nerve terminals, ACh stimulates postjunctional cholinergic muscarinic receptors. In particular, ACh-induced contraction of airway smooth muscle (ASM) cells is mainly due to activation of the $\mathrm{M}_{3}$ subtype of muscarinic receptors. Coupling of activated muscarinic $\mathrm{M}_{3}$ receptors to cell membrane Gq protein leads to stimulation of the catalytic activity of phospholipase C (PLC), which hydrolyzes phosphatidylinositol 4,5-bisphosphate, thereby generating the two intracellular second messengers inositol 1,4,5-trisphosphate $\left(\mathrm{IP}_{3}\right)$ and 1,2-diacylglycerol (DAG). ${ }^{6}$ DAG activates protein kinase $\mathrm{C}$ (PKC), which increases the sensitivity of ASM contractile apparatus to calcium ions $\left(\mathrm{Ca}^{2+}\right)$, whereas $\mathrm{IP}_{3}$ elicits $\mathrm{Ca}^{2+}$-dependent bronchoconstriction via a rapid mobilization of $\mathrm{Ca}^{2+}$ from intracellular stores such as the sarcoplasmic reticulum. ${ }^{7}$ The subsequent remarkable increase in cytosolic $\mathrm{Ca}^{2+}$ levels is responsible for the sequential activation of $\mathrm{Ca}^{2+}$-calmodulin complex, myosin light chain kinase, and actin-myosin contractile apparatus..$^{7-9}$ Furthermore, the enhanced bronchoconstrictive cholinergic tone occurring in COPD also results from the overexpression of muscarinic $\mathrm{M}_{3}$ receptors, associated with an upregulation of $\mathrm{M}_{3}$ receptor-coupled signaling pathways. ${ }^{10,11} \mathrm{In}$ this regard, it is noteworthy that key proinflammatory stimuli involved in COPD pathobiology, including cigarette smoke and tumor necrosis factor- $\alpha$, are able to stimulate Gq protein expression. $^{12,13}$

These molecular mechanisms can be effectively neutralized by currently used inhaled bronchodilators. In fact, LAMA act as potent competitive antagonists of airway muscarinic receptors, while LABA are powerful functional antagonists of bronchoconstriction. ${ }^{14}$ In both cases, these drugs are able to markedly counteract the exaggerated cholinergic bronchomotor tone affecting the airways of COPD patients. Within this evolving therapeutic scenario, tiotropium bromide represents the first, most studied, and most used LAMA for COPD treatment., ${ }^{2,15,16}$ Olodaterol is a new LABA recently introduced in clinical practice, characterized by very interesting therapeutic properties. ${ }^{17}$ Therefore, acting by different pharmacological mechanisms, tiotropium and olodaterol can reciprocally potentiate their broncodilating actions. Such a dual bronchodilation has been successfully tested in several clinical trials evaluating in COPD patients the effects of fixed-dose combinations (FDC) of tiotropium and olodaterol, assembled in the same inhaler that simultaneously delivers the two drugs. ${ }^{18}$ On the basis of the above considerations, the aim of this concise review article is to outline the mechanisms of action of tiotropium and olodaterol, as well as to discuss the efficacy and safety of tiotropium/ olodaterol co-formulations in COPD treatment.

\section{Mechanism of action and therapeutic profile of tiotropium}

Tiotropium bromide is a cornerstone of inhaled bronchodilator therapy, and its introduction in clinical practice provided a prominent evolution within the context of pharmacological competitive antagonism of muscarinic receptors. Highaffinity binding of tiotropium to transmembrane Gq-coupled airway muscarinic $M_{3}$ receptors inhibits ACh-dependent and $\mathrm{IP}_{3}$-mediated release of $\mathrm{Ca}^{2+}$ from intracellular stores, thus completely preventing cholinergic bronchoconstriction (Figure 1). The effective and long-lasting blockade of muscarinic $\mathrm{M}_{3}$ receptors, operated by tiotropium, is due to its very slow dissociation rate from these receptors. ${ }^{19}$ The molecular basis of such a highly durable residence time of tiotropium at a level of $M_{3}$ receptors has been recently elucidated in terms of chemical drug-receptor interactions. In particular, the aromatic portion of the drug deeply penetrates into a hydrophobic region of the $M_{3}$ receptor, where the hydroxyl groups of tiotropium form strong double hydrogen bonds with a specific asparagine residue (N508) of the receptor protein. ${ }^{19}$ Therefore, this molecular interaction is essential for the slowly dissociating properties of tiotropium, regarding its binding pattern to the $M_{3}$ receptor. Among currently available LAMA, tiotropium occupies for the longest time the muscarinic $\mathrm{M}_{3}$ receptor, whose blockade lasts for more than 24 hours thus allowing a once-daily administration. ${ }^{20,21}$ On the contrary, tiotropium rapidly dissociates from $\mathrm{M}_{2}$ muscarinic receptors, that in human airways are predominantly located on postganglionic vagal nerve terminals, where they act as inhibitory autoreceptors which repress ACh release..$^{22,23}$ This kinetic receptor selectivity is the key mechanism underpinning the persistent bronchodilation induced by tiotropium.

With regard to lung function, the potent bronchodilating effect of tiotropium is responsible for a significant and prolonged increase in forced expiratory volume in 1 second $\left(\mathrm{FEV}_{1}\right){ }^{24} \mathrm{It}$ has also been shown that the bronchodilatory action of tiotropium does not decrease during long-term therapy, and this observation rules out the development of pharmacological tolerance. Indeed, the large multicentric trial UPLIFT (Understanding Potential Long-Term Impacts on Function with Tiotropium) involving almost 6,000 COPD patients worldwide, demonstrated that tiotropium elicited a constant $\mathrm{FEV}_{1}$ improvement throughout the overall 4-year study period, with no detectable losses of bronchodilating effectiveness during such a long time span. ${ }^{25}$ The excellent 


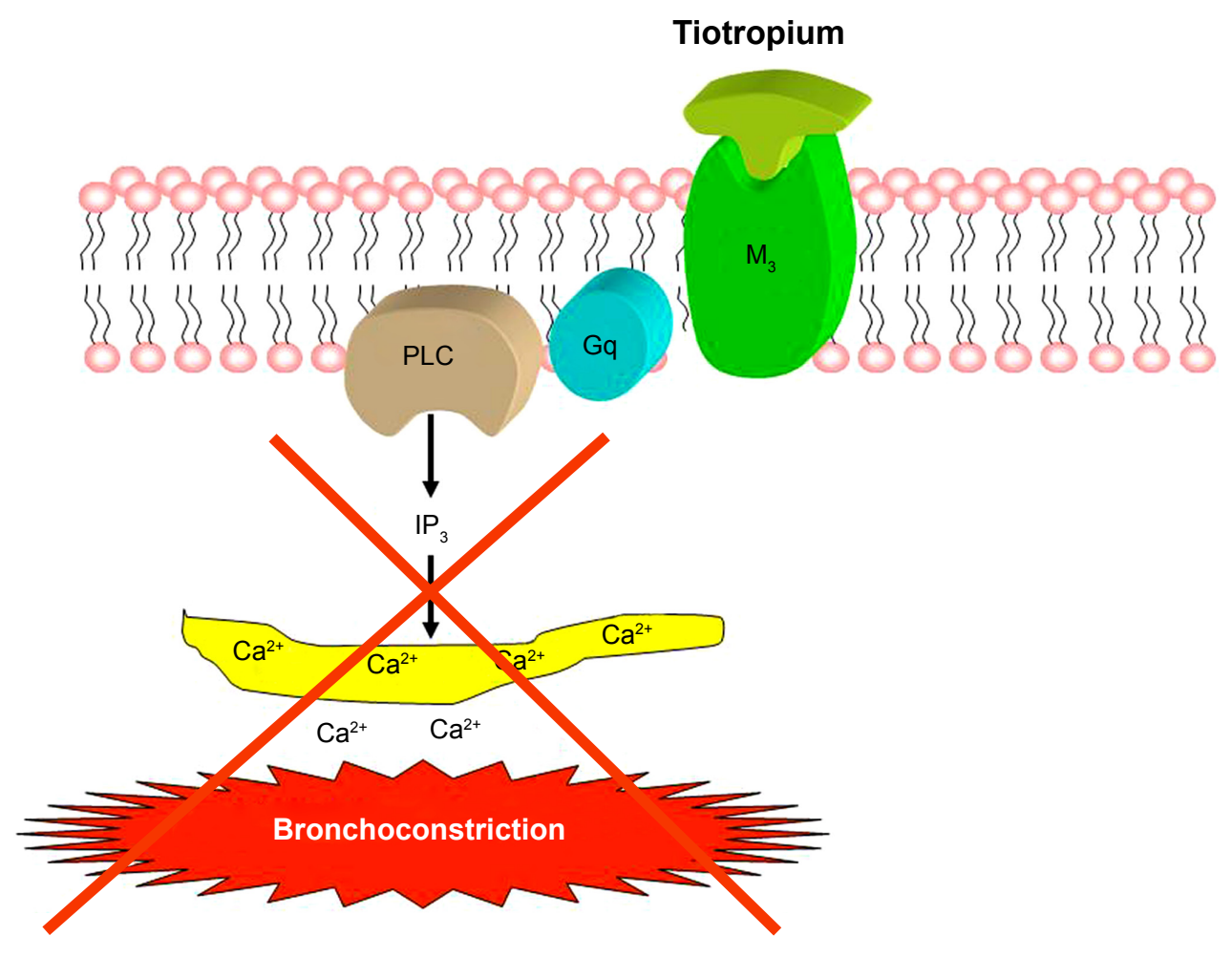

Figure I Tiotropium: mechanism of bronchodilating action.

Notes: Tiotropium lastingly binds with high affinity to muscarinic $M_{3}$ receptors, thus preventing them from activating the signal transduction pathway involving $G q$ protein and phospholipase C (PLC). As a consequence, the synthesis of the intracellular second messenger inositol I,4,5-trisphosphate $\left(\mathrm{IP}_{3}\right)$ is suppressed. Therefore, blockade of muscarinic $\mathrm{M}_{3}$ receptors by tiotropium results in an effective inhibition of bronchoconstriction mediated by $\mathrm{IP}_{3}$-dependent $\mathrm{Ca}^{2+}$ mobilization.

bronchodilatory activity of tiotropium promotes air egression from enlarged alveolar spaces, thereby decreasing lung hyperinflation. This deflating effect of tiotropium is clinically very relevant, because air trapping is the predominant cause of the main COPD symptoms, namely dyspnea and exercise intolerance. In fact, tiotropium affects static lung volumes thus reducing residual volume and functional residual capacity, as well as increasing inspiratory capacity. ${ }^{26}$ These changes result in significant improvements in both exertional dyspnea and exercise endurance. ${ }^{27}$

The therapeutic impact on lung hyperinflation also contributes to the remarkable tiotropium capability of lowering the annual rate and severity of COPD exacerbations. Indeed, lung deflation correlates better than $\mathrm{FEV}_{1}$ increase with reduction in exacerbation frequency. ${ }^{28}$ In particular, by persistently decreasing airway resistance and facilitating lung emptying, tiotropium can prevent COPD exacerbations and attenuate dyspnea during an exacerbation. On the other hand, the degree of baseline bronchial obstruction is predictive of exacerbation severity. ${ }^{29}$ Therefore, it is reasonable that severe airflow limitation fosters the development of COPD exacerbations, which in turn promote a further worsening of airway narrowing, thus triggering a deleterious and self-perpetuating vicious circle which can be interrupted by an effective and persistent bronchodilation. Tiotropium could contribute to decrease COPD exacerbations also by reducing sputum production. ${ }^{30}$ In fact, mucus hypersecretion may favor airflow obstruction and pulmonary infections, thereby enhancing the risk of COPD exacerbations. The inhibitory effect of tiotropium on sputum production is likely mediated by blockade of muscarinic $\mathrm{M}_{3}$ receptors expressed on airway mucous glands. ${ }^{31}$ Another putative mechanism potentially contributing to the positive effects of tiotropium on COPD exacerbations can be attributable to the reported anti-inflammatory activity of this drug. COPD exacerbations are indeed associated with a relevant amplification of airway inflammation. ${ }^{32}$ In this regard, it is notable that a relevant anti-inflammatory action can be exerted on lung alveolar macrophages by tiotropium via suppression of AChinduced release of leukotriene $\mathrm{B}_{4}{ }^{33}$ a powerful neutrophil chemoattractant. Moreover, tiotropium is able to inhibit the pro-inflammatory actions stimulated by ACh in neutrophils isolated from COPD patients. ${ }^{10,34}$ These anti-inflammatory effects of tiotropium appear to be also due to blockade of muscarinic $\mathrm{M}_{3}$ receptors located on inflammatory cells. ${ }^{21}$ Taken together, the above considerations suggest that several 
mechanisms are responsible for the potent preventive action on COPD exacerbations provided by tiotropium, which in this regard resulted to be equivalent to the fluticasone propionate/ salmeterol combination, and superior to either salmeterol alone or indacaterol, as shown by INSPIRE (Investigating New Standards for Prophylaxis in Reducing Exacerbations), POET (Prevention of Exacerbations with Tiotropium), and INVIGORATE (Indacaterol: Providing Opportunity to Re-engage Patients with Life) trials, respectively. ${ }^{35-37}$

\section{Mechanism of action and therapeutic profile of olodaterol}

All $\beta_{2}$-adrenergic receptor $\left(\beta_{2}\right.$-AR) agonists, including olodaterol, induce bronchodilation by relaxing ASM regardless of the nature and multitude of constricting stimuli, thus acting as functional antagonists of bronchoconstriction. These drugs occupy and activate $\beta_{2}$-ARs, which are coupled to the stimulatory $\mathrm{G}$ protein (Gs) that is in turn responsible for stimulation of adenylyl cyclase and the subsequent increase in the intracellular concentration of the second messenger cyclic AMP (cAMP) (Figure 2). ${ }^{14}$ The latter activates cAMPdependent protein kinase A (PKA), which phosphorylates several targets within the cell, ${ }^{17}$ thereby leading to inhibition of myosin light chain kinase and activation of MLC phosphatase which result in ASM relaxation. In addition, $\beta_{2}$-adrenergic agonists promote $\mathrm{Ca}^{2+}$ sequestration inside the intracellular stores and, by facilitating the opening of large conductance $\mathrm{Ca}^{2+}$-activated $\mathrm{K}^{+}$channels, these drugs induce the repolarization of ASM cell membrane. ${ }^{17}$

Olodaterol is a new LABA, recently developed for the treatment of COPD, characterized by a very long, 24-hourlasting bronchodilatory action. ${ }^{38}$ Olodaterol tightly binds to $\beta_{2}$-AR, from which this drug dissociates very slowly. ${ }^{39}$ Such a pharmacological profile is due to the formation of a highly stable ternary complex consisting of olodaterol, $\beta_{2}-A R$, and Gs protein (Figure 2). ${ }^{39}$ The long-lasting persistence on $\beta_{2}$-AR of olodaterol, with its high-affinity binding modality, results in a durable activation of the cAMP-mediated signaling pathway. On the contrary, olodaterol dissociates quite rapidly from $\beta_{1}$-AR, ${ }^{39}$ thereby exhibiting a very high $\beta_{2}$-AR selectivity. Another positive feature of olodaterol is the fast onset of its bronchodilatory action. Moreover, the pronounced $\beta_{2}$-AR selectivity of olodaterol is associated with a remarkable intrinsic activity in regard to $\beta_{2}$-AR stimulation. ${ }^{38}$ Indeed, olodaterol behaves as a nearly full $\beta_{2}$-AR agonist, whereas this drug acts as a partial $\beta_{1}$-AR agonist. ${ }^{38}$ Hence, this pharmacological profile can be therapeutically very useful, in that it provides a very effective bronchodilation, potentially paralleled by a minimization of cardiovascular side effects, mainly caused by activation of cardiac $\beta_{1}$-ARs.

Olodaterol exerts an efficacious, 24-hour-lasting protection against experimental ACh-induced bronchoconstriction in both guinea pigs and dogs. ${ }^{38}$ Used by COPD patients once daily at dosages ranging from 2 to $20 \mu \mathrm{g}$, olodaterol

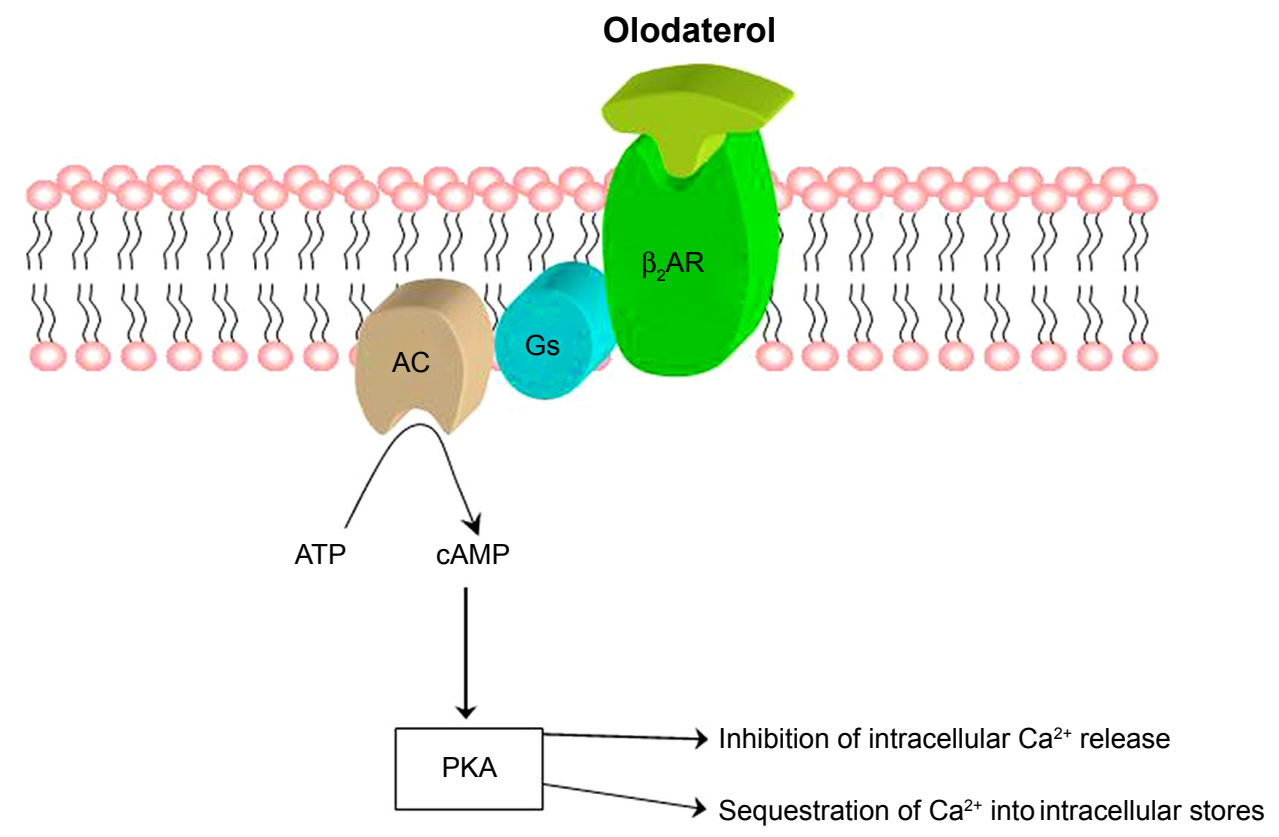

Figure 2 Olodaterol: mechanism of bronchodilating action.

Notes: Olodaterol persistently binds with high affinity and selectivity to $\beta_{2}$-adrenergic receptor ( $\beta_{2}$-AR), thus forming a very stable ternary complex, also including $\mathrm{G}$ stimulatory (Gs) protein. The subsequent, long-lasting stimulation of adenylyl cyclase (AC) and sustained increase in the intracellular concentration of second messenger cyclic AMP (cAMP) are responsible for activation of cAMP-dependent protein kinase A (PKA). PKA phosphorylates several targets involved in inhibition of Ca ${ }^{2+}$ release, as well as in sequestration of $\mathrm{Ca}^{2+}$ into intracellular stores. 
elicits dose-dependent, significant increases in $\mathrm{FEV}_{1}{ }^{40,41}$ Two replicate, randomized, double-blind, placebo-controlled, and parallel-group phase III studies, carried out in patients with moderate to very severe COPD, have shown that olodaterol 5 and $10 \mu \mathrm{g}$ significantly enhanced trough $\mathrm{FEV}_{1}$, and this bronchodilation was associated with an incidence of adverse events (AEs) comparable to that caused by placebo. ${ }^{42}$ Such findings were further corroborated by other two replicate, multicenter studies, which also demonstrated that the improvements in lung function produced by olodaterol translated into symptomatic benefits for COPD patients. ${ }^{43}$ The bronchodilating action of olodaterol was also confirmed by another randomized controlled trial, which did not find any difference in efficacy and tolerability between 5 and $10 \mu \mathrm{g}$ dosages, thus suggesting the selection of the $5 \mu \mathrm{g}$ dose in clinical practice. ${ }^{44}$ Furthermore, utilized by COPD patients at the once-daily dosage of $5 \mu \mathrm{g}$, olodaterol induced a similar 24-hour bronchodilation pattern when compared with either once-daily $10 \mu \mathrm{g}$ or twice-daily $5 \mu \mathrm{g} .{ }^{45}$ When comparatively evaluated in COPD patients under similar trial conditions, olodaterol and indacaterol, another ultralong-acting $\beta_{2}$-AR agonist, exhibited an overlapping bronchodilatory efficacy in terms of 24-hour increases in trough $\mathrm{FEV}_{1} \cdot{ }^{46}$ Overall, the safety profile of olodaterol used at both dosages of once-daily 5 and $10 \mu \mathrm{g}$, especially with regard to cardiovascular side effects, resulted to be comparable to placebo and to twicedaily administered formoterol. ${ }^{47}$

\section{Dual bronchodilation with tiotropium/olodaterol}

In patients with COPD characterized by a marked airflow limitation, in whom treatment with a single long-acting bronchodilator (LABA or LAMA) does not provide an adequate control of respiratory symptoms, a LABA/LAMA combination therapy can be usefully considered. Indeed, several LABA/LAMA combinations have been recently developed (Table 1). In particular, a potent LABA such as olodaterol induces a direct bronchodilating effect, mediated by a $\beta_{2}$-AR-dependent rapid and sustained increase in the intracellular concentration of cAMP, which is responsible for the very effective functional antagonism of ASM

Table I LABA/LAMA fixed dose combinations

\begin{tabular}{llll}
\hline LABA & LAMA & Inhaler & Company \\
\hline Olodaterol & Tiotropium & Respimat Soft Mist & Boehringer Ingelheim \\
Indacaterol & Glycopyrronium & Breezhaler & Novartis \\
Vilanterol & Umeclidinium & Ellipta & GlaxoSmithKline \\
Formoterol & Aclidinium & Genuair & Almirall \\
\hline
\end{tabular}

Abbreviations: LABA, long-acting $\beta_{2}$-adrenoceptor agonists; LAMA, long-acting muscarinic receptor antagonists.

Therapeutics and Clinical Risk Management 20I5:II contraction. Therefore, the integration of this mechanism of action with the postjunctional competitive antagonism of $M_{3}$ muscarinic receptors, namely at the level of ASM cell membrane, makes it possible for olodaterol and tiotropium, when used together, to maximize the resultant bronchodilation. ${ }^{18}$ Moreover, $\beta_{2}$-adrenergic agonists inactivate the signaling cascade underlying ACh-induced bronchoconstriction, thus enhancing the bronchodilating action of a LAMA-like tiotropium. This mechanism is mediated by cAMP-dependent transcriptional stimulation of the expression of regulator of G-protein signaling 2, which specifically inhibits the activation of the Gq protein coupled to $\mathrm{M}_{3}$ muscarinic receptors. ${ }^{48}$ Furthermore, by blocking $\mathrm{M}_{3}$ muscarinic receptors, tiotropium inhibits receptor coupling to the signal transduction pathway leading to the sequential activation of Gq and PLC, which is in turn responsible for the synthesis of DAG, the intracellular second messenger that activates PKC. ${ }^{7}$ PKC phosphorylates both $\beta_{2}$-AR and Gs protein, thereby uncoupling two key components of the signaling pathway responsible for the bronchodilating action of $\beta_{2}$-adrenergic agonists. ${ }^{49}$ Moreover, PKC can also phosphorylate and activate G-protein-coupled receptor kinase 2, an enzyme which in turn promotes the phosphorylation of specific threonine and serine residues located within the C-terminal cytoplasmatic tail of $\beta_{2}-A R$, thus further enhancing $\beta_{2}-\mathrm{AR} / \mathrm{Gs}$ uncoupling as well as facilitating binding of $\beta$-arrestins to the $\mathrm{C}$-terminus of $\beta_{2}$-AR, with subsequent intracellular receptor sequestration..$^{50,51}$ Therefore, by abrogating these effects of $\mathrm{ACh}$, tiotropium can prevent $\beta_{2}-A R$ desensitization, thus maintaining and potentiating the bronchodilating action of LABA such as olodaterol. The cooperation between LABA and LAMA also extends to the prejunctional site, namely at the level of vagal postganglionic nerve endings. Prejunctional inhibition of ACh release is indeed mediated by $\beta_{2}$-AR activation, as well as by stimulation of $M_{2}$ muscarinic autoreceptors. ${ }^{52}$ The function of prejunctional $\mathrm{M}_{2}$ autoreceptors is largely preserved by tiotropium, which rapidly dissociates from these receptors, whereas this drug blocks for a long time the postjunctional $\mathrm{M}_{3}$ muscarinic receptors, mainly responsible for bronchoconstriction and mucus hypersecretion. These positive pharmacological interactions are further amplified by the different distribution patterns of receptor targets along the bronchial tree. Indeed, the density of bronchodilating $\beta_{2}$-ARs progressively increases from proximal to distal airways, while vagal cholinergic innervation is mostly distributed within the central airways, where bronchoconstrictive muscarinic $\mathrm{M}_{3}$ receptors are present in higher numbers.$^{53}$ LAMA/LABA combinations can thus 
provide an extensive bronchodilation across the entire respiratory system.

On the basis of the pharmacological concepts as discussed in the previous section of this paper, several controlled trials have been performed to evaluate the potential benefits of tiotropium/olodaterol in COPD treatment. ${ }^{18}$ Preclinical studies, carried out in anesthetized dogs, demonstrated that the endotracheal administration of tiotropium/olodaterol combination provided, with respect to either monotherapy (tiotropium or olodaterol), a better protection against AChinduced bronchoconstriction. ${ }^{18}$ More importantly, many clinical trials conducted in COPD patients with regard to evaluation of lung function, dyspnea, and quality of life have shown that greater improvements can be achieved with tiotropium/olodaterol combination, when compared to each drug used alone. In particular, two replicate, doubleblind, randomized, 12-week studies named ANHELTO-1 and ANHELTO-2, tested in COPD patients the efficacy of tiotropium $18 \mu \mathrm{g}$ once daily, administered through the HandiHaler device, plus olodaterol $5 \mu \mathrm{g}$ once daily, delivered via the Respimat inhaler, versus tiotropium $18 \mu \mathrm{g}$ once daily (via HandiHaler) plus placebo (via Respimat). ${ }^{54}$ Acting together, tiotropium and olodaterol induced, when compared to tiotropium plus placebo, higher increases in trough (predose) $\mathrm{FEV}_{1}$ as well as in $\mathrm{FEV}_{1}$ area under the curve from 0 to 3 hours response $\left(\mathrm{FEV}_{1} \mathrm{AUC}_{0-3}\right)$, and better improvements in health status evaluated by St George's Respiratory Questionnaire. The efficacy and safety profile of tiotropium/ olodaterol combinations administered via a Respimat Soft Mist inhaler is currently being investigated by the so-called TOviTO program..$^{18}$ This is a network of ten phase 3 studies, involving more than 8,000 COPD patients with moderate to very severe disease. Within the context of the TOviTO program, TOnado-1 and TOnado-2 trials globally evaluated the effects of FDC of tiotropium ( 2.5 or $5 \mu \mathrm{g}$ ) and olodaterol $(5 \mu \mathrm{g})$, delivered once-daily through the same Respimat device for 52 weeks, which were compared with the monocomponents (tiotropium or olodaterol alone). ${ }^{55,56}$ At both dosages, tiotropium/olodaterol enhanced trough $\mathrm{FEV}_{1}$ and $\mathrm{FEV}_{1} \mathrm{AUC}_{0-3}$, producing significantly greater effects than each single drug. Moreover, the FDC of tiotropium $5 \mu \mathrm{g} /$ olodaterol $5 \mu \mathrm{g}$ improved St George's Respiratory Questionnaire total score at 24 weeks more than either tiotropium or olodaterol. Furthermore, when compared to each monotherapy component throughout the 52-week treatment period, both FDC of tiotropium + olodaterol reduced the daily use of rescue medications, and also induced a trend for decrease in the annual rate of COPD exacerbations. Recently, further valuable information has been extrapolated from a post hoc analysis of these two TOnado studies. ${ }^{57}$ Hence, FDC tiotropium + olodaterol resulted to be more effective than either monotherapy in improving lung function across all subgroups of enrolled subjects, including those who had or had not previously received a maintenance treatment with a LAMA or a LABA, as well as patients with different degrees of COPD severity. However, tiotropium/olodaterol evoked higher increases in trough $\mathrm{FEV}_{1}$ and $\mathrm{FEV}_{1} \mathrm{AUC}_{0-3}$ among patients with less severe disease. This observation is consistent with a post hoc analysis of the UPLIFT trial, which showed that tiotropium was more efficacious in patients with moderate COPD (GOLD stage 2), who achieved a slower disease progression during such a long, 4-year study.$^{58}$ Taken together, these considerations about the timing of bronchodilator therapy are very important in light of the well-known concept implying that in COPD a lung function decline proceeds at faster rates during earlier, rather than later disease stages..$^{59,60}$ This suggests that a maximal, dual-action maintenance bronchodilator treatment should probably be implemented quite precociously throughout the natural history of COPD. Consistently with such a speculation, the post hoc analysis of TOnado trials also indicates that younger patients are more responsive than older ones to the positive effects of FDC tiotropium/ olodaterol on $\mathrm{FEV}_{1} \mathrm{AUC}_{0-3} \cdot{ }^{57}$ This finding is likely attributable to the better respiratory functional response detectable in less severe patients, rather than to a primary age effect. A timely and optimal bronchodilation could also be useful in those subjects who, though not being susceptible to a rapid worsening of lung function, however, are characterized by a very high risk of developing a long-course COPD because of the occurrence of a $\mathrm{FEV}_{1}<80 \%$ of predicted value already in their early adulthood. ${ }^{61}$ In addition to eliciting higher incremental benefits with regard to changes in both trough $\mathrm{FEV}_{1}$ and $\mathrm{FEV}_{1} \mathrm{AUC}$ from 0 to 24 hours response $\left(\mathrm{FEV}_{1} \mathrm{AUC}_{0-24}\right)$ when compared to monotherapies with either tiotropium or olodaterol, according to an investigational study (VIVACITO) evaluating 24-hour dynamic respiratory function and static pulmonary volumes, FDC of tiotropium $(2.5$ or $5 \mu \mathrm{g})$ and olodaterol $(5 \mu \mathrm{g})$, delivered once-daily via Respimat inhaler for 6 weeks, also reduced lung hyperinflation more efficiently than each drug used alone. ${ }^{62}$ Indeed, tiotropium/olodaterol decreased lung residual volume and functional residual capacity to a greater extent than either tiotropium or olodaterol at both peak and trough measurements. VIVACITO is another trial of the TOviTO program. The results of VIVACITO study thus suggest that dual bronchodilation is more effective than each monotherapy in promoting lung emptying, thus implying 
that tiotropium/olodaterol lowers air trapping better than either single drug. Such findings are very important with regard to the positive actions of bronchodilator treatment on the main COPD symptoms, namely dyspnea and exercise intolerance, which are strongly dependent on lung hyperinflation, rather than on $\mathrm{FEV}_{1}$ decrease. In fact, the reported changes in static lung volumes translate into greater clinical effects, with respect to placebo, achievable by treatment with FDC tiotropium/olodaterol in terms of reduced intensity of breathing discomfort during exercise, assessed by the Borg scale. ${ }^{63}$ Other ongoing studies are included within the TOviTO program. ${ }^{18}$ In particular, OTEMTO 1 and 2 are aimed to further assess the clinical and functional outcomes of two different doses of tiotropium/olodaterol, and ENERGITO is a comparative trial which is evaluating tiotropium/olodaterol versus fluticasone propionate/salmeterol. Moreover, TORRACTO, PHYSACTO, and MORACTO 1 and 2 have been designed to assess the effects of tiotropium/olodaterol on exercise tolerance, whereas the aim of DYNAGITO is to evaluate the potential impact of the treatment with tiotropium/olodaterol on COPD exacerbations and survival. In consideration of the current, insufficient available data regarding these key issues for COPD management, ${ }^{64}$ the results of this latter study will be very important to better elucidate the effects of tiotropium/olodaterol on crucial parameters such as exacerbations and mortality.

A further advantage of the combined use of tiotropium and olodaterol is represented by the device used for this dual bronchodilator therapy. Indeed, Respimat is a soft mist inhaler which delivers these drugs regardless of inspiratory effort and patient coordination. ${ }^{65}$ Such valuable features allow one to overcome some critical limitations related to the need of hand-breathing coordination, required by pressurized metered dose inhalers, as well as to the necessity of deep inspiration, essential for activation of dry powder inhalers (DPIs). Respimat is portable, propellant-free, does not need a spacer/holding chamber, and it uses mechanical energy for actuation. ${ }^{65}$ The key technical component of Respimat is "Uniblock," a combination of filters and nozzles made of silicon and glass, which allows two converging jets of solution to collide at a controlled angle, thus generating a fine aerosol of inhalable droplets. ${ }^{66}$ The fine mist generated by Respimat makes it possible to deliver small-sized drug particles capable of also reaching peripheral airways, ie, the main site of COPD pathobiology. In fact, it has been shown that Respimat guarantees a high lung deposition of delivered drugs. ${ }^{67}$ Taken together, these characteristics of Respimat reasonably explain why this device can be satisfactorily used by almost all COPD patients, ${ }^{68}$ with a consequent increase in their adherence to inhaled treatment.

\section{Safety and tolerability}

Overall, the combined bronchodilator treatment with tiotropium/olodaterol is well tolerated and is characterized by a good safety profile in COPD patients. Given together via different devices, tiotropium and olodaterol appeared to be quite safe during the comprehensive evaluation performed within the context of ANHELTO-1 and ANHELTO-2 studies. ${ }^{54}$ Indeed, the incidence of AEs was considered to be low in both trials. Although in ANHELTO-1 more serious AEs were reported with tiotropium + olodaterol (7.1\%) when compared to tiotropium + placebo (4.6\%), the incidence of these AEs resulted to be similar in ANHELTO-2 (4.2\% and $4.7 \%$, respectively). Also when evaluated as FDC in TOnado-1 and TOnado-2 trials, tiotropium + olodaterol combinations elicited similar patterns of AEs with respect to the individual therapeutic components. ${ }^{55}$ The majority of reported AEs were mild to moderate in severity. The most common AEs were respiratory events, including upper respiratory infections which were more frequent in tiotropium/ olodaterol FDC arms, as well as COPD exacerbations, which instead resulted to be more frequent among patients undergoing treatment with either tiotropium or olodaterol monotherapies. No significant abnormalities in vital signs or laboratory parameters were found in both TOnado- 1 and TOnado-2 studies. ${ }^{55}$ With regard to the subset of patients with cardiovascular comorbidities, similar incidences of major adverse cardiac events were detected across all treatment groups. These observations were also corroborated by the results of VIVACITO trial. ${ }^{62}$ According to this study, the incidence of AEs was similar among all treatment groups, including tiotropium/olodaterol FDC $2.5 / 5 \mu \mathrm{g}$, tiotropium/ olodaterol FDC $5 / 5 \mu \mathrm{g}$, tiotropium monotherapy, olodaterol monotherapy, and placebo. The most frequent AEs were nasopharyngitis, with incidences ranging from $6.5 \%$ to $10.1 \%$, and COPD worsening, with incidences between $5.1 \%$ and $12.3 \%$. With regard to each study arm, the incidences of serious AEs were 2.9\% for placebo, 5.8\% for olodaterol alone, $3.6 \%$ for tiotropium $2.5 \mu \mathrm{g}$ alone, $2.2 \%$ for tiotropium $5 \mu \mathrm{g}$ alone, $2.9 \%$ for tiotropium/olodaterol FDC $2.5 / 5 \mu \mathrm{g}$, and $0.7 \%$ for tiotropium/olodaterol FDC $5 / 5 \mu \mathrm{g}$. No safety alarms were detected with regard to vital signs such as heart rate and arterial blood pressure. ${ }^{62}$ With regard to COPD cardiovascular comorbidities and patient survival, it is noteworthy that tiotropium HandiHaler has been shown to exert beneficial effects. ${ }^{25,69}$ However, tiotropium could 
increase the risk for tachyarrhythmias and death in subjects with either unstable cardiac disease or moderate to severe chronic kidney disease. ${ }^{70}$ Of course, these particular problems should be considered with careful attention also in regard to the eventual use of tiotropium/olodaterol combinations.

\section{Conclusion}

Tiotropium/olodaterol is a novel LAMA/LABA combination recently developed within the evolving scenario of COPD treatment. This innovative bronchodilator strategy exploits the reciprocal potentiation of the different mechanisms of action activated by LABA and LAMA. In particular, COPD patients could usefully benefit from the recently discussed synergistic interaction between LAMA and LABA, ${ }^{71}$ which can obviously provide higher advantages with respect to a simple additive cooperation. Indeed, the resulting optimization and maximization of bronchodilation makes it possible to achieve better improvements in subjective symptoms, lung function, and overall quality of life, eventually associated with clinically relevant decreases in the annual rates of COPD exacerbations. Acting together tiotropium and olodaterol provide a powerful and persistent bronchodilation, responsible for an effective lung deflation which guarantees relevant therapeutic benefits with special regard to improvements in dyspnea and exercise tolerance. In particular, the rapidly acting and long-lasting LABA olodaterol represents the ideal partner for tiotropium, the most studied and tested LAMA in both controlled trials and clinical practice. Indeed, the addition of olodaterol to tiotropium allows one to overcome the only limit of such a highly valuable LAMA, ie, its relatively late onset of action. Furthermore, once-daily delivery of tiotropium/olodaterol FDC via a very efficient and simple-to-use inhaler device such as Respimat significantly contributes to enhance the therapeutic efficacy of dual bronchodilation, as well as to increase patient adherence to inhaled treatment.

\section{Disclosure}

$\mathrm{G}$ Pelaia received lecture fees and consultancy fees from Almirall, AstraZeneca, Biofutura, Boehringer Ingelheim, Chiesi, Dompè, GlaxoSmithKline, Guidotti-Malesci, Menarini, Mundipharma, Novartis. A Vatrella received lecture fees and consultancy fees from Almirall, AstraZeneca, Boehringer Ingelheim, Chiesi, Dompè, GlaxoSmithKline, Guidotti-Malesci, Mundipharma, Novartis. R Maselli received lecture fees and consultancy fees from AstraZeneca, Boehringer Ingelheim, GlaxoSmithKline, Guidotti-Malesci, Mundipharma, Novartis. MT Busceti, L Gallelli, C Calabrese,
R Terracciano, and N Lombardo report no conflicts of interest in this work.

\section{References}

1. Vestbo J, Hurd SS, Agusti AG, et al. Global strategy for the diagnosis, management, and prevention of chronic obstructive lung disease: GOLD executive summary. Am J Respir Crit Care Med. 2013;187(4): 347-365.

2. Cazzola M, Page CP, Calzetta L, Matera MG. Pharmacology and therapeutics of bronchodilators. Pharmacol Rev. 2012;64(3):450-504.

3. Coleridge HM, Coleridge JC, Schultz HD. Afferent pathways involved in reflex regulation of airway smooth muscle. Pharmacol Ther. 1989; 42(1):1-63.

4. Groneberg DA, Quarcoo D, Frossard N, et al. Neurogenic mechanisms in bronchial inflammatory diseases. Allergy. 2004;59(11): $1139-1152$.

5. Gross NJ, Co E, Skorodin MS. Cholinergic bronchomotor tone in COPD: estimates of its amount in comparison with that in normal subjects. Chest. 1989;96(5):984-987.

6. Hall IP. Second messengers, ion channels and pharmacology of airway smooth muscle. Eur Respir J. 2000;15(6):1120-1127.

7. Pelaia G, Renda T, Gallelli L, et al. Molecular mechanisms underlying airway smooth muscle contraction and proliferation: implications for asthma. Respir Med. 2008;102(8):1173-1181.

8. Berridge MJ. Inositol trisphosphate and calcium signaling. Nature. 1993; 361(6410):315-325.

9. Somlyo AP, Somlyo AV. Signal transduction and regulation in smooth muscle. Nature. 1994;372(6503):231-236.

10. Profita M, Giorgi RD, Sala A, et al. Muscarinic receptors, leukotriene B4 production, and neutrophilic inflammation in COPD patients. Allergy. 2005;60(11):1361-1369.

11. Casarosa P, Kiechle T, Sieger P, et al. The constitutive activity of the human muscarinic M3 receptor unmasks differences in the pharmacology of anticholinergics. J Pharmacol Exp Ther. 2010;333(1):201-209.

12. Chiba Y, Murata M, Ushikubo H, et al. Effect of cigarette smoke exposure in vivo on bronchial smooth muscle contraction in vitro in rats. Am J Respir Cell Mol Biol. 2005;33(6):1574-1581.

13. Hotta K, Emala CW, Hirshman CA. TNF- $\alpha$ up-regulates Gi $\alpha$ and Gq $\alpha$ protein expression and function in human airway smooth muscle cells. Am J Physiol. 1999;276(3 Pt 1):L405-L411.

14. Barnes PJ. Biochemical basis of asthma therapy. J Biol Chem. 2011; 286(38):32899-32905.

15. Disse B, Speck GA, Rominger KL, et al. Tiotropium (Spiriva): mechanistical considerations and clinical profile in obstructive lung disease. Life Sci. 1999;64(6-7):457-464.

16. Barnes PJ. The pharmacological properties of tiotropium. Chest. 2000; 117(2 Suppl):63S-66S.

17. Cazzola M, Page CP, Rogliani P, Matera MG. $\beta_{2}$-Agonist therapy in lung disease. Am J Respir Crit Care Med. 2013;187(7):690-696.

18. Muruganandan S, Jayaram L. Profile of a fixed-dose combination of tiotropium/olodaterol and its potential in the treatment of COPD. Int J Chron Obstruct Pulmon Dis. 2015;10:1179-1189.

19. Tautermann CS, Kiechle T, Seeliger D, et al. Molecular basis for the long duration of action and kinetic selectivity of tiotropium for the muscarinic M3 receptor. J Med Chem. 2013;56(21):8746-8756.

20. Casarosa P, Bouyssou T, Germeyer S, et al. Preclinical evaluation of long-acting muscarinic antagonists: comparison of tiotropium and investigational drugs. J Pharmacol Exp Ther. 2009;330(2):660-668.

21. Kistemaker LEM, Gosens R. Acetylcholine beyond bronchoconstriction: roles in inflammation and remodeling. Trends Pharmacol Sci. 2015; 36(3):164-171.

22. Scullion JE. The development of anticholinergics in the management of COPD. Int J Chron Obstruct Pulmon Dis. 2007;2(1):33-40.

23. Restrepo RD. Use of inhaled anticholinergic agents in obstructive airway disease. Respir Care. 2007;52(7):833-851. 
24. Anzueto A, Tashkin D, Menjoge S, et al. One-year analysis of longitudinal changes in spirometry in patients with COPD receiving tiotropium. Pulm Pharmacol Ther. 2005;18(2):75-81.

25. Tashkin DP, Celli B, Senn S, et al. A 4-year trial of tiotropium in chronic obstructive pulmonary disease. $N$ Engl J Med. 2008; 359(15):1543-1554.

26. Celli B, ZuWallack R, Wang S, et al. Improvement in resting inspiratory capacity and hyperinflation with tiotropium in COPD patients with increased static lung volumes. Chest. 2003;124(5):1743-1748.

27. O'Donnell DE, Fluge T, Gerken F, et al. Effects of tiotropium on lung hyperinflation, dyspnoea and exercise tolerance in COPD. Eur Respir J. 2004;23(6):832-840.

28. Wedzicha JA, Decramer M, Seemungal TA. The role of bronchodilator treatment in the prevention of exacerbations of COPD. Eur Respir J. 2012;40(6):1545-1554.

29. Wilkinson TM, Hurst JR, Perera WR, et al. Effect of interactions between lower airway bacterial and rhinoviral infections in exacerbations of COPD. Chest. 2006;129(2):317-324.

30. Bateman ED, Rennard S, Barnes PJ, et al. Alternative mechanisms for tiotropium. Pulm Pharmacol Ther. 2009;22(6):533-542.

31. Meurs H, Dekkers BGJ, Maarsingh H, et al. Muscarinic receptors on airway mesenchymal cells: novel findings for an ancient target. Pulm Pharmacol Ther. 2013;26(1):145-155.

32. Papi A, Bellettato CM, Braccioni F, et al. Infections and airway inflammation in chronic obstructive pulmonary disease severe exacerbations. Am J Respir Crit Care Med. 2006;173(10):1114-1121.

33. Buhling F, Lieder N, Kuhlmann UC, et al. Tiotropium suppresses acetylcholine-induced release of chemotactic mediators in vitro. Respir Med. 2007;101(11):2386-2394.

34. Santus P, Buccellati C, Centanni S, et al. Bronchodilators modulate inflammation in chronic obstructive pulmonary disease. Pharmacol Res. 2012;66(4):343-348.

35. Wedzicha JA, Calverley PM, Seemungal TA, et al. The prevention of chronic obstructive pulmonary disease exacerbations by salmeterol/fluticasone propionate or tiotropium bromide. Am J Respir Crit Care Med. 2008;177(1):19-26.

36. Vogelmeier C, Hederer B, Glaab T, et al. Tiotropium versus salmeterol for the prevention of exacerbations of COPD. $N$ Engl J Med. 2011 364(12):1093-1103.

37. Decramer ML, Chapman KR, Dahl R, et al. Once-daily indacaterol versus tiotropium for patients with severe chronic obstructive pulmonary disease (INVIGORATE): a randomized, blinded, parallel-group study. Lancet Respir Med. 2013;1(7):524-533.

38. Bouyssou T, Casarosa P, Naline E, et al. Pharmacological characterization of olodaterol, a novel inhaled $\beta_{2}$-adrenoceptor agonist exerting a 24-hour-long duration of action in preclinical models. J Pharmacol Exp Ther. 2010;334(1):53-62.

39. Casarosa P, Kollak I, Kiechle T, et al. Functional and biochemical rationales for the 24-hour-long duration of action of olodaterol. J Pharmacol Exp Ther. 2011;337(3):600-609.

40. van Noord JA, Smeets JJ, Drenth BM, et al. 24-hour bronchodilation following a single dose of the novel $\beta_{2}$-agonist olodaterol in COPD. Pulm Pharmacol Ther. 2011;24(6):666-672.

41. Maleki-Yazdi MR, Beck E, Hamilton AM, et al. A randomised, placebo-controlled, Phase II, dose-ranging trial of once-daily treatment with olodaterol, a novel long-acting $\beta_{2}$-agonist, for 4 weeks in patients with chronic obstructive pulmonary disease. Respir Med. 2015; 109(5):596-605

42. Ferguson GT, Feldman GJ, Hofbauer P, et al. Efficacy and safety of olodaterol once daily delivered by Respimat in patients with GOLD 2-4 COPD: results from two replicate 48-week studies. Int J Chron Obstruct Pulmon Dis. 2014;9:629-645.

43. Koch A, Pizzichini E, Hamilton A, et al. Lung function efficacy and symptomatic benefit of olodaterol once daily delivered by Respimat in patients with GOLD 2-4 COPD: results from two replicate 48-week studies. Int J Chron Obstruct Pulmon Dis. 2014;9:697-714.
44. Feldman GJ, Bernstein JA, Hamilton A, et al. The 24-h FEV time profile of olodaterol once daily via Respimat and formoterol twice daily via Aerolizer in patients with GOLD 2-4 COPD: results from two replicate 6-week crossover studies. SpringerPlus. 2014;3:419.

45. Joos JF, Aumann JL, Coeck C, et al. A randomised, double-blind, four-way, crossover trial comparing the 24-h $\mathrm{FEV}_{1}$ profile for oncedaily versus twice-daily treatment with olodaterol, a novel long-acting $\beta_{2}$-agonist, in patients with chronic obstructive pulmonary disease. Respir Med. 2015;109(5):606-615.

46. Roskell NS, Anzueto A, Hamilton A, et al. Once-daily long-acting $\beta$-agonists for chronic obstructive pulmonary disease: an indirect comparison of olodaterol and indacaterol. Int J Chron Obstruct Pulmon Dis. 2014;9:813-824.

47. McGarvey L, Niewoehner D, Magder S, et al. One-year safety of olodaterol once daily via Respimat in patients with GOLD 2-4 chronic obstructive pulmonary disease: results of a pre-specified pooled analysis. COPD. 2015; doi:10.3109/15412555.2014.991864.

48. Holden NS, Bell MJ, Rider CF, et al. $\beta_{2}$-Adrenoceptor agonist-induced RGS2 expression is a genomic mechanism of bronchoprotection that is enhanced by glucocorticoids. Proc Natl Acad Sci U S A. 2011; 108(49):19713-19718.

49. Pelaia G, Marsico SA. Regulation of $\beta_{2}$-adrenergic receptors and the implications for bronchial asthma: an update. Monaldi Arch Chest Dis. 1994;49(2):125-130.

50. Chuang TT, Iacovelli L, Sallese M, et al. G protein-coupled receptors: heterologous regulation of homologous desensitization and its implications. Trends Pharmacol Sci. 1996;17(11):416-421.

51. Penn RB. Embracing emerging paradigms of $G$ protein-coupled receptor agonism and signaling to address airway smooth muscle pathobiology in asthma. Naunyn Schmiedebergs Arch Pharmacol. 2008; 378(2):149-169.

52. Matera MG, Page CV, Cazzola M. Novel bronchodilators for the treatment of chronic obstructive pulmonary disease. Trends Pharmacol Sci. 2011;32(8):495-506.

53. Barnes PJ. Distribution of receptor targets in the lung. Proc Am Thorac Soc. 2004;1(1):345-351.

54. ZuWallack R, Allen L, Hernandez G, et al. Efficacy and safety of combining olodaterol Respimat and tiotropium HandiHaler in patients with COPD: results of two randomized, double-blind, active controlled studies. Int J Chron Obstruct Pulmon Dis. 2014;9:1133-1144.

55. Buhl R, Maltais F, Abrahams R, et al. Tiotropium and olodaterol fixeddose combinations versus mono-components in COPD (GOLD 2-4). Eur Respir J. 2015;45(4):969-979.

56. Rabe KF. Treatment of COPD and the TOnado trial: a tempest in a teapot? Eur Respir J. 2015;45(4):869-871.

57. Ferguson GT, Flezar M, Korn S, et al. Efficacy of tiotropium + olodaterol in patients with chronic obstructive pulmonary disease by initial severity and treatment intensity: a post hoc analysis. Adv Ther. 2015; 32(6):523-536.

58. Decramer M, Celli B, Kesten S, et al. Effect of tiotropium on outcomes in patients with moderate chronic obstructive pulmonary disease (UPLIFT): a prespecified subgroup analysis of a randomized controlled trial. Lancet. 2009;374(9696):1171-1178.

59. Bridevaux P-O, Gerbase MW, Probst-Hensch NM, et al. Long-term decline in lung function, utilization of care and quality of life in modified GOLD stage 1 COPD. Thorax. 2008;63(9):768-774.

60. Vestbo J, Edwards LD, Scanlon PD, et al. Changes in forced expiratory volume in 1 second over time in COPD. $N$ Engl J Med. 2011; 365(13):1184-1192.

61. Lange P, Celli B, Agusti A, et al. Lung-function trajectories leading to chronic obstructive pulmonary disease. $N$ Engl J Med. 2015;373(2): $111-122$.

62. Beeh K-M, Westerman J, Kirsten A-M, et al. The 24-hour lung-function profile of once-daily tiotropium and olodaterol fixed-dose combination in chronic obstructive pulmonary disease. Pulm Pharmacol Ther. 2015;32:53-59. 
63. Maltais F, Iturri JG, Kirsten A, et al. Effects of 12 weeks of once-daily tiotropium and olodaterol fixed-dose combination on exercise endurance in patients with COPD. Thorax. 2014;69(Suppl 2):A186-A187.

64. Cazzola M, Rogliani P, Ora J, Matera MG. Olodaterol + tiotropium bromide for the treatment of chronic obstructive pulmonary disease. Expert Rev Clin Pharmacol. 2015;8(5):529-539.

65. Brand P, Hederer B, Austen G, et al. Higher lung deposition with Respimat soft mist inhaler than HFA-MDI in COPD patients with poor technique. Int J Chron Obstruct Pulmon Dis. 2008;3(4):763-770.

66. Dalby RN, Eicher J, Zierenberg B. Development of Respimat soft mist inhaler and its clinical utility in respiratory disorders. Med Devices. 2011;4:145-155.

67. Pitcairn G, Reader S, Pavia D, et al. Deposition of corticosteroid aerosol in the human lung by Respimat soft mist inhaler compared to deposition by metered dose inhaler or by Turbuhaler dry powder inhaler. J Aerosol Med. 2005;18(3):264-272.
68. Dekhuijzen PNR, Vincken W, Virchow JC, et al. Prescription of inhalers in asthma and COPD: towards a rational, rapid and effective approach. Respir Med. 2013;107(12):1817-1821.

69. Mathioudakis AG, Kanavidis P, Chatzimavridou-Grigoriadou V, et al. Tiotropium HandiHaler improves the survival of patients with COPD: a systematic review and meta-analysis. J Aerosol Med Pulm Drug Deliv. 2014;27(1):43-50.

70. Mathioudakis AG, Mastoris I, Chatzimavridou-Grigoriadou V, et al. The risk of tachyarrhythmias in patients with moderate-to-severe chronic kidney disease receiving tiotropium bromide. Int J Cardiol. 2015; 197:105-106.

71. Calzetta L, Matera MG, Cazzola M. Pharmacological interaction between LABAs and LAMAs in the airways: optimizing synergy. Eur J Pharmacol. 2015;761:168-173.

\section{Publish your work in this journal}

Therapeutics and Clinical Risk Management is an international, peerreviewed journal of clinical therapeutics and risk management, focusing on concise rapid reporting of clinical studies in all therapeutic areas outcomes, safety, and programs for the effective, safe, and sustained use of medicines. This journal is indexed on PubMed Central, CAS,
EMBase, Scopus and the Elsevier Bibliographic databases. The manuscript management system is completely online and includes a very quick and fair peer-review system, which is all easy to use. Visit http://www.dovepress.com/testimonials.php to read real quotes from published authors. 